\title{
Vocal cord paralysis associated with coalworkers' pneumoconiosis and progressive massive fibrosis
}

\author{
TM SHERANI, GD ANGELINI, SP PASSANI, EG BUTCHART \\ From the Department of Cardiothoracic Surgery, University Hospital of Wales, Cardiff
}

Vocal cord paralysis commonly results from disease affecting the vagus nerve or its recurrent laryngeal branches, somewhere between the jugular foramen and its entrance into the larynx. It is rarely caused by an intralaryngeal lesion.' In the thorax the left recurrent laryngeal nerve is more vulnerable than the right, since it pursues a longer intrathoracic course, coming into contact with mediastinal lymph nodes and looping around the arch of the aorta. The right recurrent laryngeal nerve is related only to the apex of the right lung. ${ }^{2}$ Left vocal cord paralysis associated with a mass in the lung is usually of sinister significance, implying a bronchogenic carcinoma that cannot be resected because of subaortic lymph node disease. We report a case of paralysis of the left vocal cord associated with longstanding progressive massive fibrosis.

\section{Case report}

A 68 year old retired coalminer with pneumoconiosis and progressive massive fibrosis presented in December 1983 with a history of persistent loss of voice beginning while singing with a male voice choir. He had never been a cigarette smoker. Physical examination showed nothing abnormal. Chest radiography at the time of admission to hospital (fig) showed a $5 \mathrm{~cm}$ lobulated mass adjacent to the left hilum, which to judge by previous radiographs had been present for many years, slowly increasing in size. The upper mediastinum was drawn to the left. There was background nodularity in both lungs consistent with coalminers' pneumoconiosis. The heart shadow was within normal limits. Laryngoscopy showed paralysis of the left vocal cord with no intrinsic laryngeal lesion. Bronchoscopy showed slight distortion of the main carina, extensive coal pigmentation of the medial wall of the right main bronchus suggesting erosion by pneumoconiotic nodes, and some kinking and rigidity of the intermediate bronchus. No abnormality was seen in the left bronchial tree. At mediastinoscopy many enlarged, hard, black pneumoconiotic lymph nodes were seen around both left

Address for reprint requests: Dr GD Angelini, Department of Thoracic Surgery, University Hospital of Wales, Heath Park, Cardiff.

Accepted 25 May 1984 and right main bronchi. Biopsy of these nodes showed gross pneumoconiotic infiltration with no evidence of neoplasm.

\section{Discussion}

In their course from the brain stem to the larynx the recurrent laryngeal nerve fibres follow a path that brings them into contact with many structures. Pathological processes in these structures can interfere with nerve function by pressure, stretching, or disruption. ${ }^{2}$ In the thorax the left recurrent laryngeal nerve is more commonly affected than the right owing to its longer course. ${ }^{23}$ Many authors have reported carcinoma of the lung as the most common neoplastic cause of vocal cord paralysis. ${ }^{124}$ In an extensive review of recurrent laryngeal nerve compression De Grant found that tumours were the most frequent cause and that the paralysis was most often unilateral. Bronchial carcinoma was the cause in half the cases, oesophageal carcinoma in $20 \%$, and carcinoma of the thyroid in $10 \%$. Acquired cardiovascular disease may also cause vocal cord

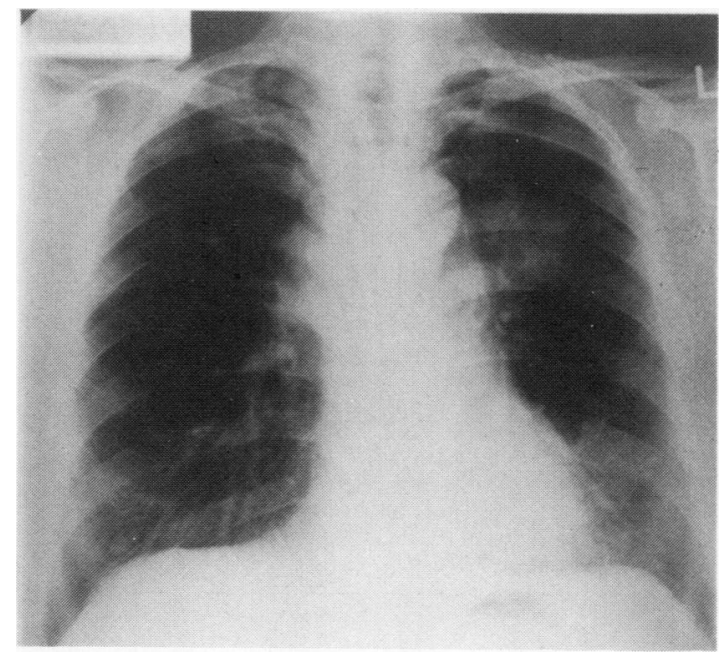

Posteroanterior chest radiograph on admission. 
paralysis. Cardiomegaly, aortic arch aneurysm, and mitral stenosis with gross enlargement of the left atrium may compress or stretch the left recurrent laryngeal nerve. ${ }^{67}$

The concern in this patient was the possibility of a bronchogenic carcinoma superimposed on pre-existing progressive massive fibrosis, a combination often difficult to diagnose, especially as the tumour may be slow to grow in a fibrotic lung. Careful scrutiny of serial chest radiographs, however, showed very little change in the appearance of the progressive massive fibrosis over many years and the patient was a lifelong non-smoker. Bronchoscopy showed no lesion in the left bronchial tree to suggest malignancy. Mediastinoscopy confirmed the clinical impression that the distortion of the mediastinum was due to progressive massive fibrosis and the associated grossly pneumoconiotic lymph nodes. Only one similar case has previously been reported, ${ }^{8}$ but in that instance neither bronchoscopy nor mediastinoscopy with biopsy of mediastinal nodes was carried out. Left vocal cord palsy occurring in the presence of fibrotic disease of the left hilum may not therefore always be of sinister significance.

The patient's voice improved slightly during his stay in hospital. In view of this we decided to review his condition in six months' time before considering teflon injection of the affected vocal cord to restore his voice.

\section{References}

' Parnell FW, Brahdemburg JH. Vocal cord paralysis: a review of 100 cases. Laryngoscope 1970;80: 1036-45.

2 Titche LL. Causes of recurrent laryngeal nerve paralysis. Arch Otolaryngol 1976;102:259-61.

${ }^{3}$ Cunning DS. Unilateral vocal cord paralysis. Ann Otol 1955;64:487.

${ }^{4}$ Hippler EG, et al. Cause of vocal cord paralysis. Mayo Clin Proc 1955; 30:518-21.

${ }^{5}$ De Grant JB. Recurrent nerve compression Acta Otolaryngol Belg 1970;24:520-54.

- Morgan AA, Murrant AS. Left vocal cord paralysis and dysphagia in mitral valve disease. Br Heart $J$ 1980;43:470-3.

7 Dolowitz DA, Lewis CS. Left vocal cord paralysis associated with cardiac disease. Am J Med 1948;4:856-62.

${ }^{8}$ Capezzuto A. Scoliosis and a recurrent nerve syndrome: Folia Med (Napoli) 1967;50(3):162-7. 